\title{
PENGARUH RELASI GENDER DAN PENGAMBILAN KEPUTUSAN TERHADAP KINERJA GURU SEKOLAH MENENGAH PERTAMA NEGERI (SMP NEGERI) DI KECAMATAN BEKASI SELATAN KOTA BEKASI
}

\author{
RATU DIAN HATIFAH ${ }^{*}$
}

\begin{abstract}
The objective of this research is to know the effect of gender relation and decision making toward job performance of the teachers at State Junior High School at south Bekasi district, Bekasi City. The research was conducted using survey method with quantitative approach and path analysis technique. The population of this research is 201 teachers. Research samples selected as much as 134 teachers using simple random sampling technique. The data obtained through questionnaires and analyzed using path analysis techniques. Based on the results of data analysis in this research it is concluded: (1) the gender relation have positive direct effect to job performance; (2) the decision making have positive direct effect to job performance; (3) the gender relation have positive direct effect to decision making. The performance can be improved through improvement of gender relation and the decision making.
\end{abstract}

Keywords: job performance, gender relation, and decision making

\section{PENDAHULUAN}

Di Kecamatan Bekasi Selatan, Kota Bekasi, Provinsi Jawa Barat, terdapat 4 (empat) Sekolah Menengah Pertama (SMP) Negeri, yang diampu oleh 201 orang guru, terdiri dari 69 orang guru laki-laki dan 132 orang guru perempuan. Dari data tersebut menunjukkan bahwa jumlah guru perempuan lebih banyak dibandingkan dengan guru laki-laki, namun pada posisi sebagai pengambil keputusan (Kepala Sekolah) didominasi oleh guru laki-laki sebanyak tiga orang dan hanya satu orang Kepala Sekolah perempuan. Data dan fakta tersebut menunjukkan bahwa jumlah guru perempuan lebih banyak ternyata tidak menjamin posisi, kedudukan, status dan peran perempuan seimbang atau sama dengan laki laki.

Berdasarkan data tersebut, bahwa permasalahan gender dalam bidang pendidikan masih tampak jelas, terutama dalam pengelolaan pendidikan dan sumber daya manusia. Dalam pengelolaan pendidikan masih ditemukan kesenjangan perolehan akses, partisipasi dan keterlibatan perempuan dalam pengambilan keputusan, yang sering disebut dengan kesenjangan gender. Salah satu faktor yang mempengaruhi adanya permasalahan gender dalam bidang pendidikan adalah faktor sosial budaya. Hal ini sesuai dengan pendapat Hubeis (2010:90), bahwa "Gender adalah suatu konsep yang menunjuk pada suatu sistem peranan dan hubungannya antara perempuan dan lelaki yang tidak ditentukan oleh perbedaan biologis, akan tetapi ditentukan oleh lingkungan sosial, politik dan ekonomi. Membicarakan persoalan gender berarti membahas persoalan relasi sosial antara perempuan dan laki-laki yang dipertautkan dengan pembagian kerja dan tanggungjawab, serta bagaimana cara relasi itu dibangun dan dikonstruksikan secara sosial dan budaya oleh masyarakat.

Menurut Rahayu Relawati, (2011:6), bahwa "kesenjangan gender dalam pembangunan dianggap pelanggaran terhadap hak-hak asasi manusia yang perlu dieliminasi melalui upaya-upaya yang sistematis dan terprogram. Ketidaksetaraan tersebut pada akhirnya

\footnotetext{
* Tenaga Ahli DPR RI Fraksi Partai Golkar
} 
melahirkan ketidakadilan yang merugikan salah satu pihak, terutama perempuan". Upaya menghilangkan kesenjangan gender dalam pendidikan didorong oleh kesepakatan Dakar tentang pendidikan berkeadilan gender, yang ditindaklanjuti oleh Pemerintah melalui UU. No 20/2003 dan Permen No. 84/2008 diperkuat Instruksi Presiden Nomor 9 Tahun 2000 tentang Pengarusutamaan Gender dalam Pembangunan Nasional.

Relasi gender dalam organisasi sekolah menggambarkan relasi sosial yang berhubungan dengan peran, tugas, hak-hak dan tanggungjawab professional guru sebagai pendidik, yang dikonstruksikan secara sosial dan budaya serta didukung oleh aturan main yang disepakati organisasi sekolah. Relasi gender yang terbangun sangat menentukan keberhasilan sekolah mencapai tujuannya, karena relasi gender tersebut berkaitan erat dengan sejauh mana seorang guru dapat meletakkan perannya dalam menjalankan tugas, cara berpikir, menganalisa dan cara bertindak guru terhadap sesuatu hal terkait dengan lingkungan kerjanya.

Dalam proses pengambilan keputusan, umumnya Kepala Sekolah memberi ruang yang luas bagi keterlibatan para guru untuk ikut serta dalam pengambilan keputusan melalui proses pertukaran informasi dan pendapat dalam suatu forum diskusi atau rapat sekolah. Sedangkan kualitas partisipasi guru dalam proses pengambilan keputusan, sangat terkait dengan dua aspek, yakni pemahaman terhadap permasalahan yang sedang dibahas dan kemauan untuk memberi masukan sebagai aspirasi dalam proses pengambilan keputusan. Partisipasi guru dalam pengambilan keputusan adalah bagaimana guru memberi pandangan mereka sebagai sesuatu yang bermakna untuk meningkatkan kinerja sekolah.

\section{Kinerja}

Kinerja dipahami sebagai prestasi kerja atau prestasi sesungguhnya yang dicapai seseorang dalam bekerja (job performance atau actual performance). Menurut Gibson (2009:372), "job performance is the outcomes of jobs that relate to the purposes of the organization such as quality, efficieny, and other criteria of effectiveness". Kinerja adalah hasil pekerjaan yang berhubungan dengan tujuan organisasi, seperti kualitas, efisiensi, dan kriteria efektifitas lainnya.

Sejalan dengan Herold D. Stolovich dan Erica T. Keeps (1992:14). bahwa "job performance is a set of results achieved to refer to the act of achieving the expected execution of a $j o b^{\prime \prime}$. Kinerja adalah seperangkat hasil yang dicapai untuk merujuk pada tindakan pencapaian pelaksanaan suatu pekerjaan yang diharapkan. Sedangkan menurut Rothman dan Coetzer (2003:1) "job performance is multi-dimensional construct which indicates how well employees perform their tasks, the initiative they take and the resourcefulness they show in solving problems". Kinerja mengindikasikan bagaimana pekerja menyelesaikan tugasnya, cara mereka memanfaatkan kemampuan sumber daya yang dimiliki, waktu dan energi yang mereka gunakan untuk menyelesaikan tugas. Berdasarkan pendapat tersebut bahwa kinerja merupakan prestasi kerja atau hasil kerja, baik kualitas maupun kuantitas yang dicapai oleh seseorang atau sekelompok orang pada suatu periode waktu tertentu dalam melaksanakan tugasnya sesuai dengan tanggung jawab yang diberikan kepadanya.

Minner (1992:612) mengemukakan, bahwa "job performance is a group and individual behavioral conformity with the behavior expeted by the organization". Pendapat tersebut menjelaskan bahwa kinerja adalah kesesuaian perilaku kelompok dan individu dengan perilaku yang diharapkan oleh organisasi. Definisi kinerja tersebut menghubungkan kinerja dengan perilaku kelompok organisasi. Colquitt, Lapine dan Wesson (2011:37) mengemukakan bahwa," Job performance is the value of a set of behaviors 
of employees who contribute positively or negatively to achieve organizational goals. Performance has three dimensions, namely task performance, citizenship behavior and counter productive behavior. Kinerja adalah nilai dari perilaku karyawan yang berkonstribusi secara positif atau negatif untuk mencapai tujuan organisasi. Kinerja memiliki tiga dimensi, yaitu perilaku tugas, perilaku moral dan perilaku menantang. Griffin (1992:464) berpendapat, bahwa "job performance is the totality of behavior related to work organization wishes to display". Kinerja adalah totalitas perilaku yang berhubungan dengan pekerjaan yang diharapkan organisasi untuk ditampilkan. Ivancevich, Konopaske dan Matteson (2007:109), menjelaskan bahwa "job performance may be viewed as a function of the capacity to perform, the opportunity to perform, willingness to perform". Kinerja dapat dipandang sebagai fungsi kapasitas untuk mewujudkan kesempatan, kemauan untuk mewujudkan kinerja. Kapasitas untuk mewujudkan kinerja, berhubungan dengan seberapa baik keterampilan, kemampuan, pengetahuan, dan pengalaman terkait dengan pekerjaan.

Miner (1992:612) mengemukakan, bahwa "job performance is a group and individual behavioral conformity with the behavior expected by the organization". Pendapat tersebut menjelaskan bahwa kinerja adalah kesesuaian perilaku kelompok dan individu dengan perilaku yang diharapkan oleh organisasi. Definisi kinerja tersebut menghubungkan kinerja dengan perilaku kelompok organisasi, berbeda dengan Colquitt, LePine, Wesson yang menekankan kinerja sebagai bentuk perilaku individu.

Sedangkan Steve M Jex (2009:80) mengemukakan, bahwa "job performance related to the knowledge of the work, setting goals and competencies in relation to the job". Kinerja berhubungan dengan pengetahuan tentang pekerjaan, penentuan tujuan dan kompetensi sehubungan dengan pekerjaan tersebut. Pengetahuan tentang pekerjaan ditentukan oleh kemampuan kognitif dan pengalaman kerja. Jadi kinerja berhubungan dengan kompetensi yang berkaitan dengan pekerjaan.

Berdasarkan pendapat para ahli tersebut, maka dapat disintesiskan, bahwa kinerja adalah perilaku pegawai yang berkonstribusi secara positif atau negatif untuk mencapai tujuan organisasi dengan indikator tanggung jawab kerja, insiatif kerja, kualitas Kerja, dan semangat kerja.

\section{Relasi Gender}

Gender erat kaitannya dengan relasi antara laki-laki dan perempuan, serta cara bagaimana relasi itu dibangun dan didukung oleh masyarakat. Menurut Unger dan Crawford (1992:272), "gender is a difference between women and men are socially constructed rather than on biological differences alone". Gender merupakan perbedaan antara perempuan dan laki-laki yang dikontruksi secara sosial bukan berdasarkan perbedaan biologis semata. Pengertian gender tersebut termasuk membicarakan relasi antara lakilaki dan perempuan, serta cara bagaimana relasi itu dibangun dan didukung oleh masyarakat. Jadi relasi gender bukanlah sesuatu yang kaku dan kekal. Relasi gender dapat berubah sesuai dengan perkembangan sosial dan budaya masyarakat yang melingkupinya.

Menurut Hazel Reeves and Sally Baden (2000:18), bahwa "gender relations' carries the potential not just for differentiation and differential empowerment, but also dominance, disadvantage, and economic, educational and political inequality. This is true regardless of whether women and men live, learn and work along side each other, or live largely parallel rather than 'integrated' lives. Relasi gender berkaitan dengan kekuasaan dan dominasi struktur kesempatan hidup, pembagian kerja yang lebih luas antara perempuan dan laki-laki dalam ekonomi, pendidikan dan politik, pada gilirannya diperkuat oleh sistem budaya, agama serta ideologi yang berkembang dalam masyarakat. Leonard dalam Paula Nelson 
(1996:9), mengemukakan bahwa, "gender relations are power relations, through which men and male values have superordinate status over women and female values, and socialization into gender roles is an integral part of the maintenance of the patriarchal power structure." Relasi gender adalah hubungan antar kekuatan, di mana nilai laki-laki adalah super ordinat di atas nilai perempuan dan secara sosial peran gender adalah bagian yang integral dari struktur kuasa dari patriarki. Sedangkan Helen Tierney (1991:153), dalam Women's Studies Encyclopedia gender didefinisikan sebagai "gender relations are differences in their roles, behaviors, and mental and emotional characteristics between women and men developed by the community". Relasi gender didefinisikan sebagai perbedaan dalam peran, perilaku, dan karakteristik mental dan emosional antara perempuan dan laki-laki yang dikembangkan oleh masyarakat.

Spike Peterson dan Anne Sissom Runyan (1993:5) menjelaskan bahwa, "gender related is of men and women and the specific attribute of masculinity and feminity vary dramatically over time and across cultures, Men are not exclusively leaders and warriors, and women are not exclusively in charge of maintaining the home and caring for children." Relasi gender dimaksud bukanlah sebuah atribut tertentu yang melekat pada laki-laki dan perempuan yang sangat bervariasi dari waktu dan lintas budaya bahwa pria tidak selalu eksklusif menjadi pemimpin atau seorang prajurit dan perempuan juga tidak eksklusif bertugas menjaga dan mengasuh anak. Kenyataan seperti inilah yang berdampak pada kehidupan perempuan dan laki-laki, baik di ranah domestik rumah tangga maupun di ranah publik yaitu dunia kerja, dunia pendidikan. Senada dengan pendapat Ostergaard (1992), bahwa, "gender related to the quality and relationships formed in relation to the structures of power and domination in the life chances of women and men, more extensive division of labor and in turn rooted in the conditions of production and reproduction system reinforced by culture, religion and ideology prevailing in community." Relasi gender berkaitan dengan kualitas dan relasi yang dibentuk dalam kekuasaan dan dominasi struktur kesempatan hidup perempuan dan laki-laki, pembagian kerja yang lebih luas yang pada gilirannya berakar pada kondisi produksi dan reproduksi yang diperkuat oleh sistem budaya, agama dan ideologi yang berlaku dalam masyarakat. Selanjutnya Mosse (1996:57), bahwa "gender relations is a set of roles assigned to women and men, not biologically and this role may change according to culture, social class, age and ethnic background". Relasi gender adalah seperangkat peran yang diberikan kepada perempuan dan laki-laki, bukan secara biologis dan peran ini dapat berubah sesuai dengan budaya, kelas sosial, usia dan latar belakang etnis. Dengan demikian relasi gender akan bervariasi berdasarkan waktu, tempat, budaya serta pengalaman hidup.

Berdasarkan pendapat para ahli tersebut dapat disintesiskan, bahwa relasi gender merupakan hubungan sosial antara laki-laki dan perempuan yang mengacu pada peran dan tanggung jawab, bukan berdasarkan pertimbangan biologis yang diperkuat oleh sistem budaya, agama dan ideologi yang berlaku dalam masyarakat dengan indikator pemahaman, akses, partisipasi, kontrol dan manfaat.

\section{Pengambilan Keputusan}

Pengambilan keputusan adalah aktivitas manajemen berupa pemilihan suatu alternatif tindakan dari beberapa alternatif yang telah dirumuskan sebelumnya untuk memecahkan suatu masalah dalam manajemen. Menurut Luthans (2009:340), "decision making is almost universally defined as choice between alternative." Pengambilan keputusan didefinisikan sebagai pemilihan dari beberapa alternatif. Schermerhorn, Hunt, dan Osborn (2005:314) menjelaskan, "decision making is the process of choosing a course of action for dealing with problem and opportunity". Pengambilan keputusan adalah proses memilih 
tindakan untuk mengatasi masalah dan peluang. Hal yang senada diungkapkan oleh Ivancevich, Konopaske dan Matteson (2008:381), "decision making, which is defined as the process of choosing a particular action that deals with a problem or opportunity". Pengambilan keputusan, yang didefinisikan sebagai proses memilih tindakan tertentu yang berhubungan dengan masalah atau peluang.

Kontz dan Weichrich (1988:144) menjelaskan "decision making is defined as selection of action from among alternatives, it is at the core of planning". Pengambilan keputusan didefinisikan sebagai pemilihan tindakan dari alternatif perencanaan. Kinicki dan Kreitner (2008:249) mendeskripsikan pengambilan keputusan adalah "identifying and choosing solutions that lead to a desired and result". Hal ini menunjukkan bahwa pengambilan keputusan adalah mengidentifikasi dan memilih solusi yang sesuai dengan tujuan. Lebih lanjut dijelaskan, bahwa "logical four step approach do decision making identifying the problem, generating solution, selecting a solution, implementing and evaluating the solution". Dalam proses pengambilan keputusan yang rasional memiliki empat langkah, yaitu: mengidentifikasi masalah, mengembangkan alternatif, memilih keputusan yang terbaik, melaksanakan dan menilai keputusan.

Jones dan George (2007:332), mendefinisikan bahwa "decision making is the process by which manager respond to opportunities and threats that confront them by analyzing the options and making determinations". Pengambilan keputusan adalah proses dimana manajer merespon peluang dan ancaman yang menghadang mereka dengan menganalisis pilihan dan membuat penentuan. Pengambilan keputusan adalah aktivitas manajemen berupa pemilihan suatu alternatif tindakan dari beberapa alternatif yang telah dirumuskan sebelumnya untuk memecahkan suatu masalah dalam manajemen.

Sedangkan Grenbeng dan Baron (1997:358) menjelaskan,"decision making as the process of making choices from among several alternative". Pengambilan keputusan adalah proses menentukan pilihan dari beberapa alternatif yang ada. Keputusan yang baik akan membantu individu, kelompok dan organisasi untuk mencapai prestasi atau mencapai tujuan organisasi. Pengambilan keputusan dapat diartikan sebagai "proses memilih", yaitu memilih salah satu atau beberapa alternatif terbaik. Sesuatu yang berkaitan dengan pilihan adalah jika seseorang berhadapan dengan lebih dari satu alternatif pilihan. Jika hanya terdapat satu alternatif dan tidak tersedia alternatif lainnya maka hal itu bukanlah sesuatu yang dapat dipilih. Pada dasarnya kedua definisi ini menyatakan bahwa pengambilan keputusan merupakan proses pemilihan tindakan tertentu dari suatu masalah dan kesempatan.

Menurut pendapat Colquitt, Lapine dan Wesson (2011:268), mengemukakan bahwa "decision making return to the process of generating and choosing from a set of alternatif to solve a problem". Pengambilan keputusan merupakan proses menghasilkan dan memilih dari serangkaian alternatif untuk memecahkan masalah. Dengan pengertian bahwa mengambil atau membuat suatu keputusan berarti memilih satu dari sekian banyak alternatif.

Berdasarkan pendapat yang dikemukakan oleh para ahli tersebut di atas, maka dapat disintesiskan pengambilan keputusan adalah proses pemilihan satu alternatif tindakan dari beberapa alternatif untuk memecahkan suatu masalah dalam mewujudkan tujuan organisasi dengan indikator: aspiratif, komunikatif, akomodatif, inovatif, dan korektif

\section{METODE PENELITIAN}

Penelitian ini dilaksanakan kepada guru Sekolah Menengah Pertama Negeri (SMPN) di Kecamatan Bekasi Selatan Kota Bekasi, dilaksanakan selama 3 (tiga) bulan. 
Metode yang digunakan dalam penelitian ini adalah survey dengan menggunakan teknik kausal. Populasi adalah guru SMP Negeri di Kecamatan Bekasi Selatan, Kota Bekasi yang berjumlah 201 guru dengan jumlah sampel sebanyak 134 orang guru. Data yang dikumpulkan dalam penelitian dijaring melalui kuesioner yang berupa skala penilaian (rating scale) dengan sebaran skor antara 1 sampai dengan 5.

Setelah dilakukan analisis deskriptif dilanjutkan dengan uji persyaratan analisis berupa uji normalitas, uji linearitas data dan keberartian regresi, dilakukan uji hipotesis dengan menggunakan teknik analisis jalur (path analysis).

\section{HASIL DAN PEMBAHASAN}

\section{Pengaruh Langsung Relasi Gender Terhadap Kinerja}

Hasil penelitan ini menunjukkan bahwa relasi gender memberikan pengaruh positif secara langsung terhadap kinerja. Besarnya pengaruh tersebut ditunjukkan oleh koefisien korelasi 0,564 dan koefisien jalur 0,478. Hal ini menujukkan bahwa relasi gender dapat meningkatkan kinerja guru. Hasil penelitian ini sejalan dengan pendapat Colquitt, Lapine dan Wesson (2011:37) mengemukakan bahwa "job performance is the value of a set of behaviors of employees who contribute positively or negatively to achieve organizational goals. Performance has three dimensions, namely task performance, citizenship behavior and counter productive behavior". Kinerja adalah nilai dari perilaku karyawan yang berkonstribusi secara positif atau negatif untuk mencapai tujuan organisasi. Kinerja memiliki tiga dimensi, yaitu perilaku tugas (task performance), perilaku moral (citizenship behavior) dan perilaku menantang (counter productive behavior).

Pendapat Giffin (1992:464), bahwa "job performance is the totality of behavior related to work organization wishes to display. Kinerja adalah totalitas perilaku yang berhubungan dengan pekerjaan yang diharapkan organisasi untuk ditampilkan. Sementara relasi gender sangat terkait erat dengan kinerja, sebab relasi gender merupakan relasi sosial antara perempuan dan laki-laki yang dipertautkan dengan pembagian kerja dan tanggungjawab, serta bagaimana cara relasi itu dibangun dan dikonstruksikan secara sosial dan budaya oleh masyarakat.

Hasil penelitian tersebut sejalan dengan pendapat Helen Tierney (1991:153), bahwa "gender relations are differences in ther oles, behaviors, and mental and emotional characteristics between women and men developed by the community". Relasi gender didefinisikan sebagai perbedaan dalam peran, perilaku, dan karakteristik mental dan emosional antara perempuan dan laki-laki yang dikembangkan oleh masyarakat. Relasi gender di masyarakat sangat dipengaruhi oleh faktor-faktor sejarah, budaya, ekonomi dan agama yang mengakar sangat kuat secara turun temurun di kalangan masyarakat.

Peran gender dalam sebuah organisasi secara perspektif akan membedakan cara berpikir, merasa, menilai dan berperilaku. Perbedaan peran gender ini terbentuk oleh faktor-faktor idieologis, sejarah, etnis, ekonomi dan kebudayaan. Relasi gender lebih berhubungan dengan perbedaan peran perempuan dan laki-laki sebagai hasil konstruksi sosial, budaya dan psikologis. Relasi gender dalam organisasi kerja akan memberi konstribusi positif terhadap pencapaian kinerja apabila dalam suatu organisasi (termasuk sekolah) terbangun keadilan dan kesetaraan gender. Sebab keadilan gender akan terwujud seiring dengan terbangunnya relasi antara laki-laki dan perempuan yang berbasis pada kesetaraan untuk memperoleh kesempatan dan hak-haknya, agar mampu berperan dan berpartisipasi dengan indikator partisipasi, kebersamaan, interaksi dan pengorganisasian. Senada dengan pendapat Ostergaard (1992), bahwa, "gender related to the quality and relationships formed in relation to the structures of power and domination in the 
life chances of women and men, more extensive division of labor and in turn rooted in the conditions of production and reproduction system reinforced by culture, religion and ideology prevailing in community." Relasi gender berkaitan dengan kualitas dan relasi yang dibentuk dalam kekuasaan dan dominasi struktur kesempatan hidup perempuan dan laki-laki, pembagian kerja yang lebih luas yang pada gilirannya berakar pada kondisi produksi dan reproduksi yang diperkuat oleh sistem budaya, agama dan ideologi yang berlaku dalam masyarakat. Selanjutnya Mosse (1996:57), bahwa "gender relations is a set of roles assigned to women and men, not biologically and this role may change according to culture, social class, age and ethnic background". Relasi gender adalah seperangkat peran yang diberikan kepada perempuan dan laki-laki, bukan secara biologis dan peran ini dapat berubah sesuai dengan budaya, kelas sosial, usia dan latar belakang etnis. Dengan demikian relasi gender akan bervariasi berdasarkan waktu, tempat, budaya serta pengalaman hidup.

Merujuk pada hasil penelitian dan teori tersebut, maka diketahui bahwa terdapat pengaruh langsung positif relasi gender terhadap kinerja guru. Dengan kata lain bahwa semakin tinggi relasi gender yang terbangun diantara para guru dalam suatu sekolah, maka akan semakin besar pengaruhnya terhadap peningkatan kinerja guru.

\section{Pengaruh Langsung Pengambilan Keputusan Terhadap Kinerja}

Hasil penelitan ini menunjukkan bahwa pengambilan keputusan memberikan pengaruh positif secara langsung terhadap kinerja. Besarnya pengaruh tersebut ditunjukkan oleh koefisien korelasi 0,410 dan koefisien jalur 0,237. Hasil penelitian ini sejalan dengan pendapat Luthans (2009:340) mengemukakan bahwa, "decision making is almost universally defined as choice between alternative". Pengambilan keputusan didefinisikan sebagai pemilihan dari beberapa alternatif. Pengambilan keputusan memegang peranan penting karena keputusan yang diambil merupakan hasil pemikiran akhir yang harus dilaksanakan oleh anggota atau organisasi.

Hasil penelitian ini sejalan dengan pendapat Gibson (2009:372), yang menyatakan bahwa "job performance is the outcomes of jobs that relate to the purposes of the organization such as quality, efficieny, and other criteria of effectiveness". Kinerja adalah hasil pekerjaan yang berhubungan dengan tujuan organisasi, seperti kualitas, efisiensi, dan kriteria efektifitas lainnya. Hal tersebut harus didukung dengan proses pengambilanan keputusan sebagaimana diungkapkan oleh Kinicki dan Kreitner (2008:249), pengambilan keputusan adalah "identifying and choosing solutions that lead to a desired and result". Mengidentifikasi dan memilih solusi yang sesuai dengan tujuan. Dalam proses pengambilan keputusan yang rasional memiliki empat langkah, yaitu: mengidentifikasi masalah, mengembangkan alternatif, memilih keputusan yang terbaik, melaksanakan dan menilai keputusan. Pengambilan keputusan dikenal sebagai hal yang penting bagi organisasi dan manajemen untuk mencapai tujuan yang efektif. Dalam hal ini menunjukkan bahwa pengambilan keputusan menentukan efektif atau tidak efektifnya pencapaian kinerja.

Menurut Schermerhorn, Hunt, dan Osborn (2005:314), bahwa, "decision making is the process of choosing a course of action for dealing with problem and opportunity". Pengambilan keputusan adalah proses memilih tindakan untuk mengatasi masalah dan peluang. Hal ini berarti pengambilan keputusan merupakan proses dimana manajer merespon peluang dan ancaman yang menghadang mereka dengan menganalisis pilihan dan membuat penentuan. Kualitas keputusan yang diambil manajer adalah tolok ukur keefektifan. Walaupun pengambilan keputusan merupakan proses 
manejerial, namun dalam proses pengambilan keputusan pada dasarnya memerlukan partisipasi aktif dari setiap individu yang ada dalam organisasi dan member pengaruh langsung terhadap kinerja. Sedangkan Grenbeng dan Baron (1997:358) menjelaskan, "decision making as the process of making choices from among several alternative". Pengambilan keputusan adalah proses menentukan pilihan dari beberapa alternatif yang ada. Keputusan yang baik akan membantu individu, kelompok dan organisasi untuk mencapai prestasi atau mencapai tujuan organisasi. Pengambilan keputusan dapat diartikan sebagai "proses memilih", yaitu memilih salah satu atau beberapa alternatif terbaik. Sesuatu yang berkaitan dengan pilihan adalah jika seseorang berhadapan dengan lebih dari satu alternatif pilihan. Jika hanya terdapat satu alternatif dan tidak tersedia alternatif lainnya maka hal itu bukanlah sesuatu yang dapat dipilih. Pada dasarnya kedua definisi ini menyatakan bahwa pengambilan keputusan merupakan proses pemilihan tindakan tertentu dari suatu masalah dan kesempatan.

Merujuk pada hasil penelitian dan teori tersebut, maka diketahui bahwa, terdapat pengaruh langsung positif pengambilan keputusan terhadap kinerja guru. Dengan kata lain semakin tinggi tingkat partisipasi guru dalam proses pengambilan keputusan, maka akan memberi pengaruh yang positif terhadap meningkatnya kinerja guru.

\section{Pengaruh Langsung Relasi Gender Terhadap Pengambilan Keputusan}

Hasil penelitan ini menunjukkan bahwa relasi gender memberikan pengaruh positif secara langsung terhadap pengambilan keputusan. Besarnya pengaruh tersebut ditunjukkan oleh koefisien korelasi 0,362 dan koefisien jalur 0,362. Hasil penelitian ini sejalan dengan pendapat Rae Andre (2008:64), yang mengemukakan bahwa "decision making is a logical process that develop alternatives and selects the best among them". Pengambilan keputusan adalah proses logis yang mengembangkan alternatif dan memilih yang terbaik dari beberapa alternatif tersebut. Pendapat senada disampaikan oleh Simon (1997:55), mengemukakan bahwa "every decision elements of two kinds which were called factual and values elements respectively". Setiap pengambilan keputusan adalah memilih alternatif berdasarkan fakta dan nilai yang membawa kepada sesuatu pengertian tentang alternatif keputusan yang benar, dan menjelaskan perbedaan antara permasalahan-permasalahan administrasi. Dengan pengertian bahwa mengambil atau membuat keputusan berarti memilih satu dari sekian banyak alternatif. Dalam hal ini seseorang yang akan mengambil suatu keputusan menghadapi tidak hanya satu pilihan, tetapi banyak pilihan alternatif yang tersedia baginya untuk dipilih, sehingga memerlukan masukan atau inoput dari orang lain sebagai relasinya.

Hasil penelitian juga sejalan dengan pendapat Leonard dalam Paula Nelson (1996:9), bahwa "gender relations are power relations, through which men and male values have superordinate status over women and female values, and socialization into gender roles is an integral part of the maintenance of the patriarchal power structure. Relasi gender adalah hubungan antar kekuatan, di mana nilai laki-laki adalah super ordinat di atas nilai perempuan dan secara sosial peran gender adalah bagian yang integral dari struktur kuasa dari patriarki.

Hal senada diungkapkan oleh Walklate, S (2004:74), bahwa "social structures that support the formation of gender relations, namely the division of labor by gender, gender-based power, and sexuality". Struktur sosial mendukung pembentukan relasi gender yaitu pembagian kerja berdasarkan gender, kekuasaan berbasis gender dan seksualitas. Struktur ini mendefinisikan kondisi feminitas dan maskulinitas yang dikonstruksikan 
dan juga direkonstruksikan. Pendapat tersebut menggambarkan bahwa dua karakteristik seseorang yang berbeda dapat mempengaruhi sikapnya dalam proses pengambilan keputusan. Seseorang yang memiliki sisi feminim cenderung akomodatif dalam pengambilan keputusan, sedangkan seseorang yang memiliki sisi maskulin yang dominan cenderung menggunakan gaya otokratik yang menghendaki segala keputusan yang akan diambil harus berasal darinya. Seseorang bisa saja memiliki sisi feminim yang kuat, sehingga menjadi akomodatif dalam proses pengambilan keputusan, sebaliknya seseorang yang dominan maskulinnya, cenderung sangat otoriter, hanya fokus pada aturan dan tugas, tidak peduli terhadap lingkungan sekitarnya, termasuk kondisi bawahannya.

Merujuk pada hasil penelitian dan teori tersebut, maka diketahui bahwa terdapat pengaruh langsung positif relasi gender terhadap pengambilan keputusan guru. Dengan kata lain semakin tinggi relasi gender yang tebangun antara para guru dalam suatu sekolah, maka akan semakin tinggi tingkat partisipasi guru dalam proses pengambilan keputusan.

\section{PENUTUP}

Kesimpulan: Berdasarkan hasil penelitian dan hasil analisis data, maka dapat diperoleh beberapa kesimpulan sebagai berikut: (1) Relasi gender berpengaruh langsung positif terhadap kinerja guru. Artinya peningkatan relasi gender yang terbangun diantara para guru, maka akan mengakibatkan peningkatan kinerja Guru SMP Negeri Kecamatan Bekasi Selatan, (2) Pengambilan keputusan berpengaruh langsung positif terhadap kinerja guru. Artinya meningkatnya partisipasi guru dalam proses pengambilan keputusan mengakibatkan peningkatan kinerja guru, dan (3) Relasi gender berpengaruh langsung positif terhadap pengambilan keputusan. Artinya meningkatnya relasi gender yang terbangun diantara para guru akan mengakibatkan peningkatan partisipasi guru dalam proses pengambilan keputusan.

Saran: Berdasarkan kesimpulan penelitian tersebut, maka dapat diajukan saran-saran sebagai berikut: (1) Saran untuk guru. diharapkan dapat meningkatkan relasi gender dengan cara-cara sebagai berikut: saling memahami peran dan fungsi guru, meningkatkan akses informasi, meningkatkan partisipasi dalam pengambilan keputusan, melakukan kontrol terhadap pelaksanaan kebijakan sekolah dan mengambil manfaat dari kebijakan; (2) Saran untuk kepala sekolah terkait dengan pengambilan keputusan agar dapat meningkatkan kinerja guru adalah sebagai berikut: tingkatkan aspirasi dalam pengambilan keputusan, komunikatif dalam pengambilan keputusan, akomodatif terhadap usulan dan saran, inovatif memunculkan gagasan dan korektif untuk perbaikan kebijakan, (3) Saran untuk penelitian yang akan datang, bahwa belum semua masalah kinerja guru dapat terjawab melalui penelitian ini, masih banyak faktor yang berpotensi mempengaruhi kinerja guru yang harus dijelaskan melalui penelitian selanjutnya misalnya kompetensi, kualitas kerja, disiplin, kepemimpinan, dan lain-lain. 


\section{DAFTAR RUJUKAN}

Colquitt, LePine, Wesson, Organizational Behavior: lmproving Performance And Commitment in The Workplace. New York: McGraw-Hill. Second Edition. 2009.

Fred Luthans, Jonathan P. Doh. International Management. New York: McGraw-Hill Companies, Inc, 2009.

Griffin, R.W., Management, AITBS, Publisher and Distributor. New Delhi India, 1992.

Herbert Simon, Administrative Behavior, a Study of Decision Making Processes in Administrative Organization, New York: The Free Press, 1997.

Herold D. Stolovich dan Erica T. Keeps. Handbook of Human Performance Problem in Organization, San Fransisco: Jorney Bass Publisher, 1992.

Helen Tierney (ed), Woman's Studies Encyclopedia, New York: Peter Bedrick Book, 1991.

Hubeis, A.V.S., Pemberdayaan Perempuan dari Masa ke Masa, Bogor: IPB. Press, 2010.

Hazel Reeves and Sally Baden, Gender and Development: Concepts and Definitions Prepared for the Department for International Development (DFID) for its gender mainstreaming intranet resource February, 2000.

James L Gibson, John M, Ivanchevich dan James H Donnely, Jr, Organization : Behavior, Structure, Procesess, New York : McGraw-hill, 2009.

Jason A. Colquitt, Jeffery A. Lapine, Michael J. Wesson, Organizational Behavior Improving Performance and Commitment in the Workplace, New York: McGraw-Hill, 2011.

Jerald Grenbeng and Robert A. Baron, Behavior in organizations : understanding and managing the human side of work, Upper Saddle River, N.J. : Prentice Hall, 1997.

John R. Schermerhorn, et al. Organizational Behavior. Canada: John Wiley \& Sons, Limited, 2005.

John Ivancevich, Robert Konopaske, Michael Matteson, Organizational Behavior and Management, New York : McGraw-Hill/Irwin, 2008.

Kinicki, Angelo dan Kreitner, Robert, Organizational Behavior, Key Concepts skil \& Best Practices, New York: McGraw-Hill, 2008.

Minner, Industrial Organizational Pshycology, New York: McGraw-Hill. 1992.

Mosse, J.C. Gender dan Pembangunan, Yogyakarta: Rifka Annisa WCC dan Pustaka Pelajar, 1996.

Paula Nicolson, Gender, power and organization: a psychological perspective, Buckinghamshire: Chesham,1996. 
Relawati, Rahayu, Konsep dan Aplikasi Penelitian Gender, Bandung: PT. Muara Indah, 2011.

Rae Andre, Policy and Organisational Management, International Journal of Management Practice, Inderscience Publishers 2008.

Rothman, S. and Coetzer, E.P., The Big Five Personality Dimensions And Job Performance, SA. Journal of Industrial Psychology: 2003.

Unger, R, and Crawford. Women and Gender a Feminist Psychology, New York: McGrawHill Inc. 1992.

Walklate, S. Gender, Crime, and Criminal Justice 2nd Edition, UK: Willan Publishing, 2004. 